\title{
Violência contra o docente em uma escola estadual de ensino médio de Leópolis, norte do Paraná
}

\author{
Violence against teachers in the state school of high school in Leópolis, \\ north of Paraná
}

\author{
Pedro Henrique Carnevalli Fernandes', Patrícia Aparecida Albini Prado"
}

\begin{abstract}
RESUMO
Este artigo aborda a violência no contexto escolar, especialmente contra o docente, e os movimentos de enfrentamento dessa violência em uma escola estadual de ensino médio. O objetivo principal consistiu em compreender a violência no ambiente escolar de uma escola estadual de ensino médio, a partir da percepção dos docentes, na pequena cidade de Leópolis, localizada no Norte Pioneiro do Estado do Paraná. A metodologia utilizada foi baseada em pesquisas bibliográficas, levantamento de dados secundários acerca do município e da escola e aplicação de questionário nos docentes da referida escola. Os resultados sinalizaram que os docentes sofrem, diariamente, com a violência no ambiente escolar. Além disso, como consequência, a violência tem causado síndromes e influenciando na saúde desses docentes, causando desânimo, pânico, depressão e até a desistência da profissão. Portanto, observou-se que as escolas de pequenas cidades como espaços seguros têm se tornado uma realidade cada vez mais nostálgica.
\end{abstract}

Palavras-chave: Pequenas cidades; Violência contra o docente; Violência escolar

\section{ABSTRACT}

This paper approaches the violence in school context, especially against teachers and the movements concerning violence coping in a state school of high school. The main objective was to understand the violence in the school environment, in state schools from the teachers' perception of the small town of Leópolis, located in the Pioneer North of Paraná. The methodology used was based on bibliographic research, collecting of secondary data from the municipality and schools, and applying a questionnaire to teachers of the said school. The results signaled that many educators daily suffer from stress and anxiety as a result of the atmosphere of violence in classrooms. Moreover, as a consequence, violence has caused syndromes and has affected the health of these learning professionals, causing discouragement, panic, depression and even making them giving up on their profession. Therefore, it was found that small town schools, as secure spaces, have become an increasingly nostalgic reality.

Keywords: School violence; Small towns; Violence against teacher

\section{INTRODUÇÃO}

O fenômeno da violência está presente na sociedade contemporânea e, por isso,

vem sendo, cada vez mais, associado aos diferentes espaços, como o escolar, I Docente do Colegiado de Geografia da Universidade Estadual do Norte do Paraná E-mail: pedrofernandes@uenp.edu.br ORCID: https://orcid.org/0000-0001-7542-7912

" Graduada em Geografia pela Universidade Estadual do Norte do Paraná E-mail: patricia.albine@gmail.com ORCID: https://orcid.org/0000-0002-8961-7028 
configurando-se como uma preocupação para toda a comunidade. Assim, é recorrente, em diferentes espaços, pessoas que já foram vítimas de casos de violência, gerando, por conseguinte, uma ampliação do sentimento de medo e de insegurança e uma alteração nas relações de sociabilidade, sobretudo, enfraquecendo-as.

A violência contra a escola ocorre por meio das depredações, vandalismo, roubo, furto, agressões e ameaças contra os componentes da instituição escolar. Esse contexto não é restrito ao ambiente escolar, já que reflete a realidade social brasileira. Nessa perspectiva, a escola deixa de ser um espaço seguro, que visa atitudes de aprendizado, descobertas, respeito, amizade, harmonia, socialização e integração, para ser um espaço de diversas violências e até de medo. Nesse sentido, é preciso ampliar os debates sobre a violência nas escolas.

Além disso, este artigo se justifica pelo fato da violência ocorrer em uma cidade pequena. O estudo acerca da violência e da insegurança em pequenas cidades ainda é incipiente na Ciência Geográfica. Apesar disso, Fernandes (2017) comprovou a existência da violência em pequenas cidades do Norte do Paraná a partir de três fatores explicativos: o transbordamento do modo de vida metropolitano, o tráfico de produtos e drogas ilícitas e a ausência e/ou insuficiência dos serviços públicos de segurança.

Assim, o objetivo principal deste artigo foi compreender a violência no ambiente escolar em uma escola estadual de ensino médio a partir da percepção dos docentes localizada no município de Leópolis, no Norte do Estado do Paraná. Logo, este artigo realiza um diagnóstico da problemática da violência no ambiente escolar com a intenção de colaborar para o aprofundamento da compreensão de um fenômeno pouco explorado pela academia, mas que parece ser rotineiro nas escolas estaduais paranaenses, inclusive em cidades demograficamente pequenas.

Os objetivos específicos deste artigo foram: (i) apresentar o contexto histórico, social e político da consolidação do município de Leópolis e seu contexto atual, 
especialmente quanto aos indicadores de educação; (ii) discorrer, teoricamente, sobre a violência no ambiente escolar; (iii) transitar, empiricamente, pela violência contra o docente, identificando as violências mais enfrentam por eles; e (iv) verificar as estratégias utilizadas pelos docentes quanto à violência enfrentado no ambiente escolar, especialmente quanto à afastamentos ou problemas de saúde.

Os procedimentos metodológicos utilizados na construção deste artigo foram: (i) levantamento bibliográfico acerca dos temas da violência e da violência no ambiente escolar; (ii) levantamento de dados secundários sobre o município de Leópolis e sobre a escola pesquisada; (iii) realização de pesquisa de campo por meio de aplicação de questionário nos docentes da escola estadual de ensino médio campo de estudo; e (iv) elaboração de produtos cartográficos e da redação final deste artigo.

Em Leópolis, existem quatro escolas estaduais, sendo que para efeito de segurança, não é disponibilizado o nome da escola pesquisada. A participação dos docentes da escola de ensino médio pesquisada, por meio do preenchimento do questionário e do fornecimento de informações extras, foi maciça e significativa. No total, todos os 25 docentes atuantes na escola pesquisada responderam o questionário. Essa participação, sem colocar nenhum obstáculo, comprova que ao atender à solicitação e colaborar com a pesquisa, eles corroboram a importância e a preocupação com o tema em debate.

Quanto ao recorte espacial, o município de Leópolis, povoado a partir da década de 1930 e emancipado em 1951 (LEÓPOLIS, 2018), está localizado no Norte do Estado do Paraná, especificamente na Mesorregião Norte Pioneiro paranaense (Figura 1), a 420 quilômetros de Curitiba, capital do Estado. No último censo, em 2010, Leópolis possuía 4.145 habitantes, sendo $60 \%$ na área urbana (IBGE, 2010). No entanto, em 1970, a população total era de 12.021 habitantes e, em 1980, o município enfrentou um declínio demográfico assustador, passando a contar com 5.180 habitantes (LEÓPOLIS, 2018). 


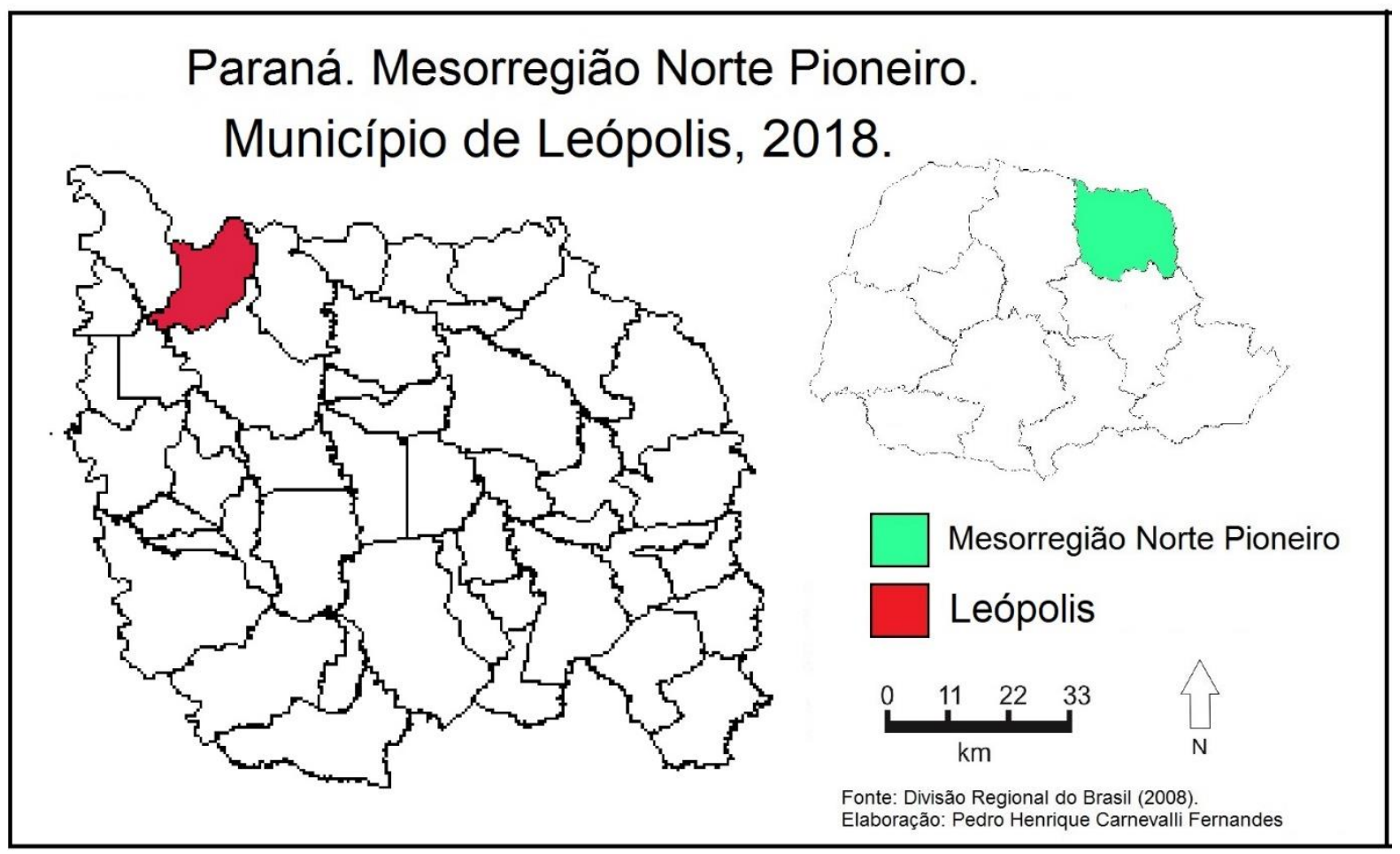

Fonte: Adaptado de IBGE (2008).

Elaboração: Pedro Henrique Carnevalli Fernandes (2018).

Segundo o Atlas (2013), sobre os aspectos socioeconômicos, o município de Leópolis apresentava, em 2000, um Índice de Desenvolvimento Humano Municipal (IDHm) de 0,742. A dimensão que mais cresceu no período de 1991 a 2000, foi à educação, com um IDH de 0,828, seguida da longevidade $(0,744)$ e renda $(0,653)$, conforme os dados do Atlas (2013).

Já considerando os dados do Instituto Paranaense de Desenvolvimento Econômico e Social, Ipardes (2017), todas as crianças de cinco a seis anos estavam nas escolas, enquanto que $3 \%$ das crianças de 11 a 13 anos estavam fora delas. Já a taxa de analfabetismo (pessoas maiores de 15 anos que declararam não serem capazes de ler e escrever um bilhete simples ou que apenas assinam o próprio nome, incluindo as que aprenderam a ler e escrever, mas esqueceram, segundo o Instituto Brasileiro de Geografia e Estatística - IBGE), era de quase 12\%, sendo que entre as pessoas mais velhas, o patamar se elevada para quase 26\% (IPARDES, 2017).

Diante disso, a discussão deste artigo é estruturada da seguinte forma, além desta introdução, das considerações finais e das referências: (i) debate teórico- 
metodológico sobre violência no ambiente escolar; e (ii) compreensão e reflexões da realidade dos docentes da escola estadual pesquisada a partir dos resultados alcançados com a aplicação do questionário nos professores da referida escola.

\section{AMBIENTE ESCOLAR E VIOLÊNCIA NA ESCOLA}

O fenômeno da violência no meio escolar se tornou um tema de debate público, sendo que a "violência é (...) mais um componente do espaço escolar e contribui efetivamente para a configuração de uma 'paisagem' marcada por sentimento de insegurança e desconfiança no outro" (LOPES, 2008, p. 36). Dialogando com isso, Soares e Machado (2014, p. 334) pontuam que a "violência constitui hoje uma das grandes preocupações da sociedade. No âmbito da escola, estampam-se cada vez mais nos jornais notícias sobre casos de agressões sofridas por professores e alunos". O resultado dessa situação é um clima de insegurança entre os professores, funcionários e alunos.

A violência no ambiente escolar é entendida por Lopes (2008) pelas ocorrências de agressões verbais, brigas, roubo, furto, indisciplina, incivilidades, violência moral, agressões física, violência contra o patrimônio público, discriminação, humilhação, desrespeito, etc. Já a violência contra o professor é compreendida como:

Toda forma de agressão física ou moral, provocada por alunos, pais de alunos e a própria instituição, no ambiente escolar, causando danos à integridade física e moral dos professores. Essa agressão é deflagrada a partir de situações do próprio ambiente escolar, caracterizando principalmente situações da dinâmica da sala de aula, como chamar atenção de alunos, atribuir nota baixa, reprovação, entre outros. $E$, ainda, por situações que envolvem assédio moral e desvalorização profissional dos docentes (SOARES, 2013, p. 32).

Para Priotto e Boneti (2009), a violência escolar pode ser entendida como uma construção social que ocorre em meio às interações entre os sujeitos no espaço escolar, enfatizando a probabilidade da violência como um processo social e institucional, em particular no que tange às relações sociais entre sujeitos diversos. Portanto, segundo os autores, todos os atos ou ações de violência, comportamentos agressivos e antissociais praticados por e entre a comunidade escolar (alunos, professores, 
funcionários, familiares) no ambiente escolar são enquadrados no conceito de violência escolar.

As consequências da violência no espaço escolar são inúmeras e variadas, dependendo do espaço, do sujeito e da comunidade no entorno. Silva (2010), por exemplo, enfatiza que a violência contra o professor prejudica a eficácia do processo de ensino-aprendizagem do aluno. Logo, a "agressão contra o docente resulta em comprometimento da sua saúde emocional, da qualidade das relações humanas, prejuízo da construção da cidadania e do processo educacional" (COSTA, 2013, p. 94).

Nesse sentido, a violência sofrida faz com que o professor adoeça e/ou adquira síndromes que o impedem de exercer adequadamente suas funções, gerando, em muitos casos, desistência da profissão. Embora o fenômeno da violência não seja recente (FERNANDES, 2017), no ambiente escolar, ela se tornou mais explícita e intensa na contemporaneidade, ou seja, "no passado, a profissão do professor era nobre (...). Atualmente, não se ensina que o professor tem que ser respeitado. (...), poucos desejam que seus filhos sejam professores" (SILVA, 2010, p. 4).

A partir disso, transformou o docente como "sendo alvo de diversos tipos de violência seja ela, física, verbal, moral e/ou psicologia" (SILVA, 2010, p. 9). Logo, o professor muitas vezes trabalha coagido e ameaçado por alunos, sobretudo os desinteressados em aprender (SODRÉ, 2012). Nesse sentido, Lopes e Gasparin (2003) apontam que a intensificação dos conflitos gera uma espécie de "guerra", onde todos perdem:

Os professores, pelo estresse físico e psíquico a que estão submetidos, e os alunos, por terem à sua frente mais um obstáculo na produção de seu conhecimento, imprescindível para o exercício da cidadania. A escola, que chegou a ser chamada de "segundo lar" ou apêndice de casa, aparece hoje, na visão de alguns, como "local perigoso", onde não há previsibilidade sobre o que pode acontecer (LOPES; GASPARIN, 2003, p. 295).

A presença mais intensa da violência no cotidiano da escola "tem aumentado a complexidade da relação professor-aluno e tornado mais agudos os conflitos próprios da relação" (LOPES; GASPARIN, 2003, p. 296). Então, as dificuldades em gerir esses conflitos revelam o que os autores chamam de "crise" na relação entre os envolvidos. 
Efetivamente, a solução para essa "crise" não pode vir com mais "crise", ou, em outras palavras, o combate contra a violência não pode acontecer com mais violência.

Segundo Abramovay e Rua (2002), a violência no meio escolar contribui para uma diminuição da qualidade do ensino e faz com que a relação professor-aluno se torne conflituosa, prejudicando o processo ensino-aprendizagem, o desenvolvimento das aulas e o projeto pedagógico. Nesse sentido, a violência que se instala no interior da escola surpreende por suas múltiplas e diversificadas manifestações (LOPES, 2001).

A violência contra os docentes "protagonizada por alunos (...) é um dos reflexos da impunidade que impera na sociedade" (SILVA, 2010, p. 1). Igualmente, como fruto de uma sociedade de classes e com uma justiça seletiva, os professores sentem-se incapazes para buscar seus direitos: "os professores evidenciaram impotência mediante os casos enfrentados nas escolas, especialmente perante os episódios em que eles estão no papel de vítima" (SOARES, 2013, p. 21). Uma explicação para isso está no fato de que na maioria das vezes não encontram apoio nas instituições e órgãos públicos (SILVA, 2010).

O crescimento da violência na escola - "quebra-quebra, agressões físicas, mortes e ameaças de morte - tem provocado reações e contrarreações que só fazem piorar o conflito, realimentando um processo que instaura a insegurança" (MARRA, 2004, p. 18) em todos os envolvidos na comunidade escolar. Por conseguinte, a escola entra nesse debate contemporâneo sobre a violência, ora como vítima da violência externa, ora como algoz, quando vista como uma instituição com sua cota própria de violência: a escola é lugar da reprodução das desigualdades sociais, de gênero, da produção da pobreza e da exclusão, tendo, portanto, sua cota de violências socioeconômicas (SCHILLING, 2004).

A violência na escola é aquela que se produz dentro do espaço escolar, sem estar ligado à natureza e às atividades da instituição escolar: quando um bando entra na escola para acertar contas das disputas que são as do bairro, a escola é apenas o lugar de uma violência que teria podido acontecer em qualquer outro local. [...] A violência à escola está ligada à natureza e às atividades da instituição escolar: quando os alunos provocam incêndios, batem nos professores ou os insultam, eles se entregam a violências que visam diretamente a instituição e aqueles que a representam. Essa violência contra a escola deve ser analisada junto com a violência da escola: uma violência institucional, simbólica, que os próprios jovens suportam através da maneira como a instituição e seus agentes os tratam (modos de 
composição das classes, de atribuição de notas, de orientação, palavras desdenhosas dos adultos, atos considerados pelos alunos como injustos ou raciais...). Esta distinção é necessária: se a escola é largamente (mas não totalmente) impotente fazse à violência na escola, ela dispõe (ainda) de margens de ação faz-se à violência à escola e da escola. (CHARLOT, 2002, p. 434-435).

Apesar de a escola ser esse espaço de materialização da violência, ela é, concomitantemente, o próprio espaço para transformação dessa realidade. Para Rosa (2010), a resolução da violência no ambiente escolar requer a participação efetiva de toda a comunidade (professores, alunos, gestores, família e sociedade). Logo, se torna urgente repensar o espaço da escola como lugar onde é possível a mudança, educar para a emancipação. Segundo Schilling (2004, p. 69), "a educação, materializada na escola, é um dos direitos humanos fundamentais para a realização de uma série de outros diretos humanos". Então, a escola organiza-se para garantir a aprendizagem de todos.

\begin{abstract}
A educação, materializada na escola, tem uma história. Nessa história, percebemos claramente o lugar que a instituição ocupa em nossa sociedade e a disputa pelo sentido desse lugar tão central e importante. A disputa pelo sentido da educação e pelo significado do papel central que a escola ocupa pode ser resumida do seguinte modo: a escola é, por momentos, vista como instituição que construirá a democracia, potencializará os talentos existentes. A escola é promotora de justiça (SCHILLING, 2004, p. 61).
\end{abstract}

A escola, instituição de portas estreitas, foi tendo suas portas ampliadas: mulheres, filhos e filhas de operários e camponeses, pessoas de religiões e etnias diferentes, etc., se avançando em educação e em direitos humanos (SCHILLING, 2004). Contribuindo nesse sentido, Silva e Salles (2010, p. 26) consideram que a escola continua a ser o lugar em que se concentra uma parte fundamental do saber. Por isso, é fundamental que as políticas públicas de formação de profissionais da educação criem possibilidades reais de enfrentamento dos problemas pelos quais passam as escolas, especialmente no que diz respeito à formação de professores conscientes e preparados (TEIXEIRA; PORTO, 2004).

A escola é fundamental para o pleno desenvolvimento do indivíduo, "devendo ser um dos contextos sociais que estimule as habilidades intelectuais, as habilidades sociais e a absorção crítica dos conhecimentos produzidos em nossa sociedade" (PEREIRA; WILLIANS, 2010, p. 47). Então, a escola deve ser referência de um local seguro 
e tranquilo já que o ambiente escolar é indispensável na vida social de qualquer indivíduo. Por isso,

A sociedade deve valorizar a profissão do educador (...) e que o professor tenha o devido apoio com acompanhamento jurídico e médico quando se sentir agredido durante o exercício de suas funções. Assim, através de debates, diálogos e comprometimento dos setores da sociedade, pode-se chegar a um compromisso às regras de convívio, onde professores e alunos sejam respeitados e valorizados com cidadãos críticos e conscientes de seus direitos e deveres (SILVA, 2010, p. 9).

Na escola estadual de ensino médio de Leópolis a violência também é uma realidade, como pôde ser constatado nos resultados do trabalho empírico, apresentados na sequência.

\section{VIOLÊNCIA CONTRA O DOCENTE NA ESCOLA ESTADUAL DE ENSINO MÉDIO DE LEÓPOLIS (PR)}

Inicialmente, apresentam-se os resultados quanto ao perfil dos respondentes. Sobre a idade, $8 \%$ dos docentes tinham entre $18-29$ anos, $16 \%$ possuíam entre 30-39 anos, $28 \%$ dos docentes estavam com idade entre 40-49 anos, 44\% tinham entre 50-59 anos e $4 \%$ dos docentes possuíam 60 anos ou mais. Houve predomínio de mulheres, com $68 \%$ dos docentes da escola, sendo que os homens representavam $32 \%$.

Sobre o local de moradia, $88 \%$ dos docentes residiam em Leópolis e 12\% moravam em Cornélio Procópio, município vizinho a 23 quilômetros de distância e sede do Núcleo Regional de Ensino. Essa proporção de docentes residentes em outra cidade tem explicação no regime de trabalho: entre os docentes da escola de ensino médio estudada, $76 \%$ atuavam em regime de trabalho concursado enquanto $24 \%$ eram atuantes pelo Processo Seletivo Simplificado (PSS) do Governo do Estado do Paraná.

A Figura 2 apresenta o tempo de atuação na profissão, independentemente do tempo que estão na escola de ensino médio de Leópolis, dos docentes respondentes. Apenas $4 \%$ estão a menos de um ano lecionando, $20 \%$ atuam entre dois e cinco anos, 12\% trabalham na educação básica de seis a dez anos e 64\% são docentes há 11 anos ou mais. 
Figura 2: Leópolis (PR). Escola Estadual de Ensino Médio. Tempo de atuação dos docentes

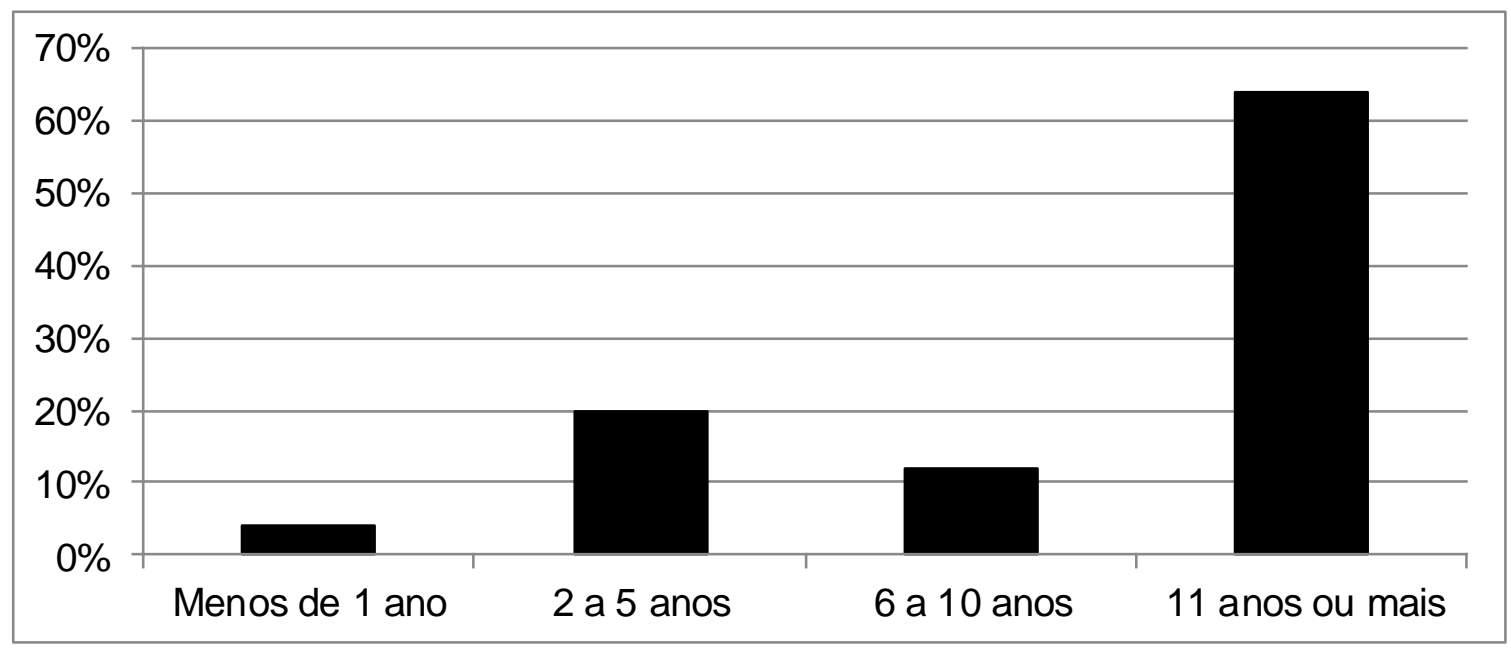

Fonte: Trabalho empírico - 2016.

Portanto, a esmagadora maioria de docentes tem experiência em sala de aula e com bagagem suficiente para uma avaliação real. Na sequência, os resultados abordam a temática da violência no ambiente escolar. A Figura 3 demostra os dados acerca da existência de violência no ambiente escolar na escola pesquisada.

Figura 3: Leópolis (PR). Escola Estadual de Ensino Médio. Percepção dos docentes quanto à existência da violência no ambiente escolar

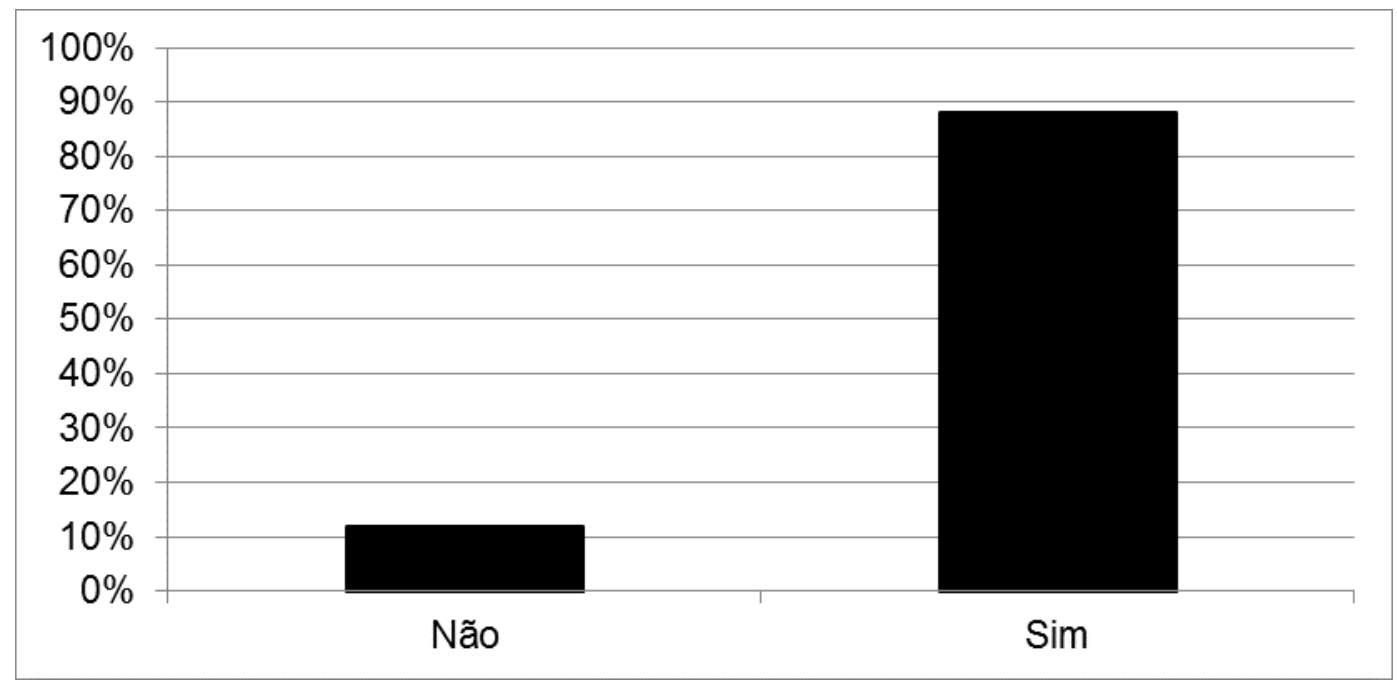

Fonte: Trabalho empírico - 2016 
Para $88 \%$ dos docentes da escola existe violência no ambiente escolar e para 12\% ela não existe. Nesse caso, mais do que demostrar que a violência está presente no cotidiano da comunidade escolar, a percepção dos docentes realça que há amplo reconhecimento e compreensão da materialização do fenômeno no local. É fundamental dialogar com a fundamentação teórica, destacando que esse fenômeno da violência ao atingir o meio escolar tem contribuído com o sentimento de insegurança e desconfiança contra os outros envolvidos na comunidade escolar (LOPES, 2008), sendo que é preciso transformar esse tema tão difuso em uma preocupação e, principalmente, objeto de combate e de políticas públicas. Além disso, reconhecer a existência da violência no espaço é um primeiro passo para iniciar ações e políticas públicas de enfrentamento.

A Figura 4 aborda a proporção de docentes que já sofreram alguma ocorrência de violência dentro da escola estudada. Já a Figura 5 apresenta as tipologias de violências enfrentadas pelos docentes da escola estadual de ensino médio de Leópolis pesquisada.

Figura 4: Leópolis (PR). Escola Estadual de Ensino Médio. Proporção de docentes que já sofreram com a violência

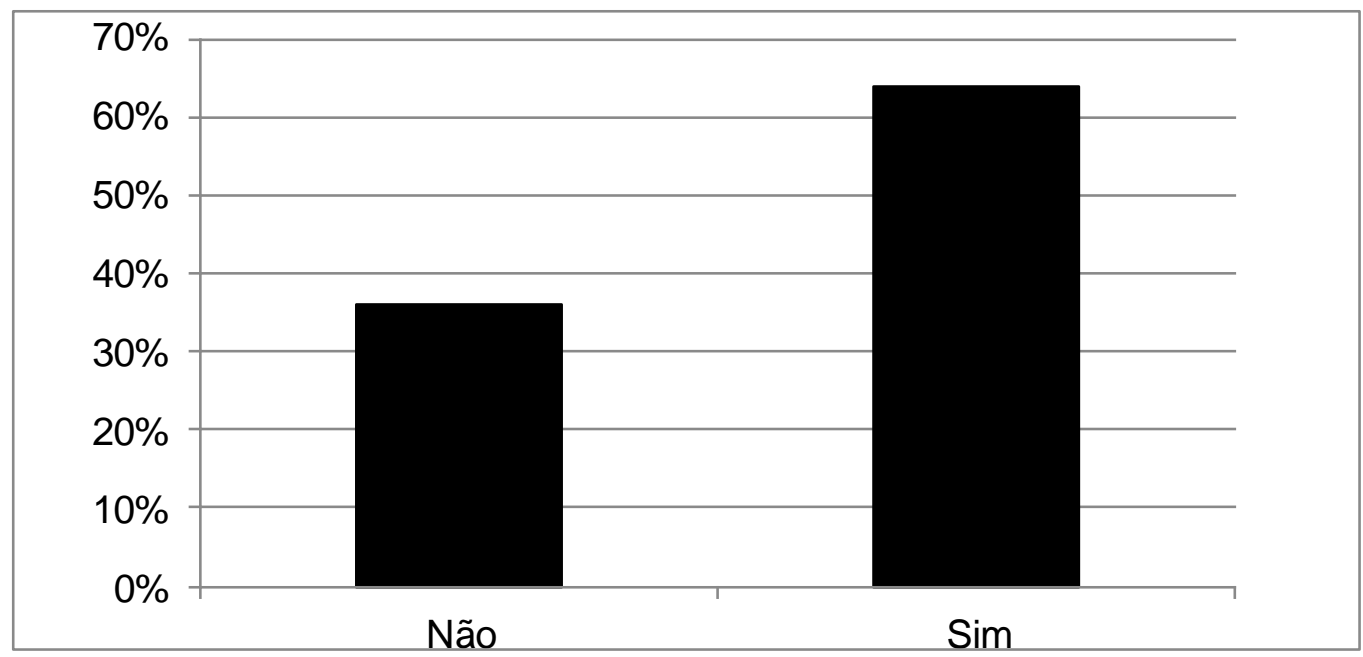

Fonte: Trabalho empírico - 2016 
Figura 5: Leópolis (PR). Escola Estadual de Ensino Médio. Violências sofridas pelos docentes

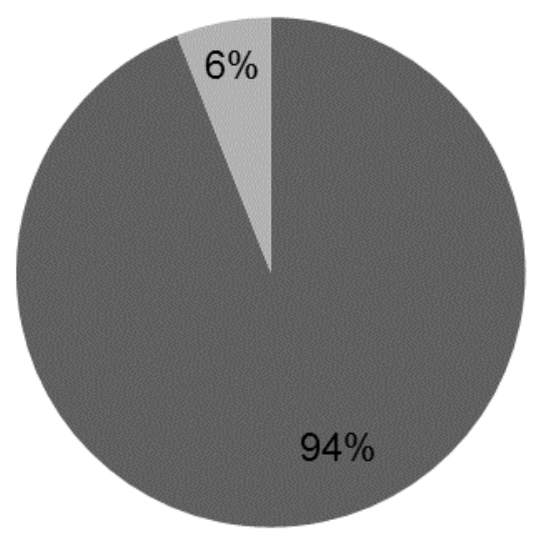

— Agressão Verbal

$\square$ Ameaça

Fonte: Trabalho empírico - 2016

É possível perceber que $64 \%$ dos docentes já sofreram violência na escola. É um resultado alarmante. Como pontua Silva (2010), essa violência contra o professor acaba por prejudicar, diretamente, a eficácia do processo de ensino-aprendizagem do aluno. Evidentemente, essa violência gera outros problemas, como o adoecimento do profissional, incluindo a saúde emocional (SILVA, 2010; COSTA, 2013). No caso do espaço, a escola, ela tem se tornado, cada vez mais, um "local perigoso" (LOPES; GASPARIN, 2003).

É importante ressaltar que não foram dadas opções de respostas, deixando o docente livre para determinar a tipologia. Assim, duas violências foram pontuadas nas respostas: agressão verbal, citada por $94 \%$ dos professores, e a ameaça, considerada por $6 \%$ dos docentes, ou seja, promessas explícitas de provocar danos ou de violar a integridade física ou moral, a liberdade e/ou bens dos educadores. É fundamental destacar que a literatura considera a ameaça e a agressão verbal como formas de violência.

Os dados seguintes tentam encontrar os principais agressores dos professores na escola estadual de ensino médio de Leópolis pesquisada. Efetivamente, todos acabam participando dessa sociedade violenta, ou seja, colegas de trabalho (servidores da escola), pais e responsáveis, além do próprio aluno. 
A Figura 6 apresenta a proporção de docentes da escola estadual de ensino médio de Leópolis pesquisada que sofreram alguma ocorrência de violência praticada por pais ou responsáveis pelos alunos.

Figura 6: Leópolis (PR). Escola Estadual de Ensino Médio. Proporção de docentes que já sofreram violência praticada por pais ou responsáveis pelos alunos

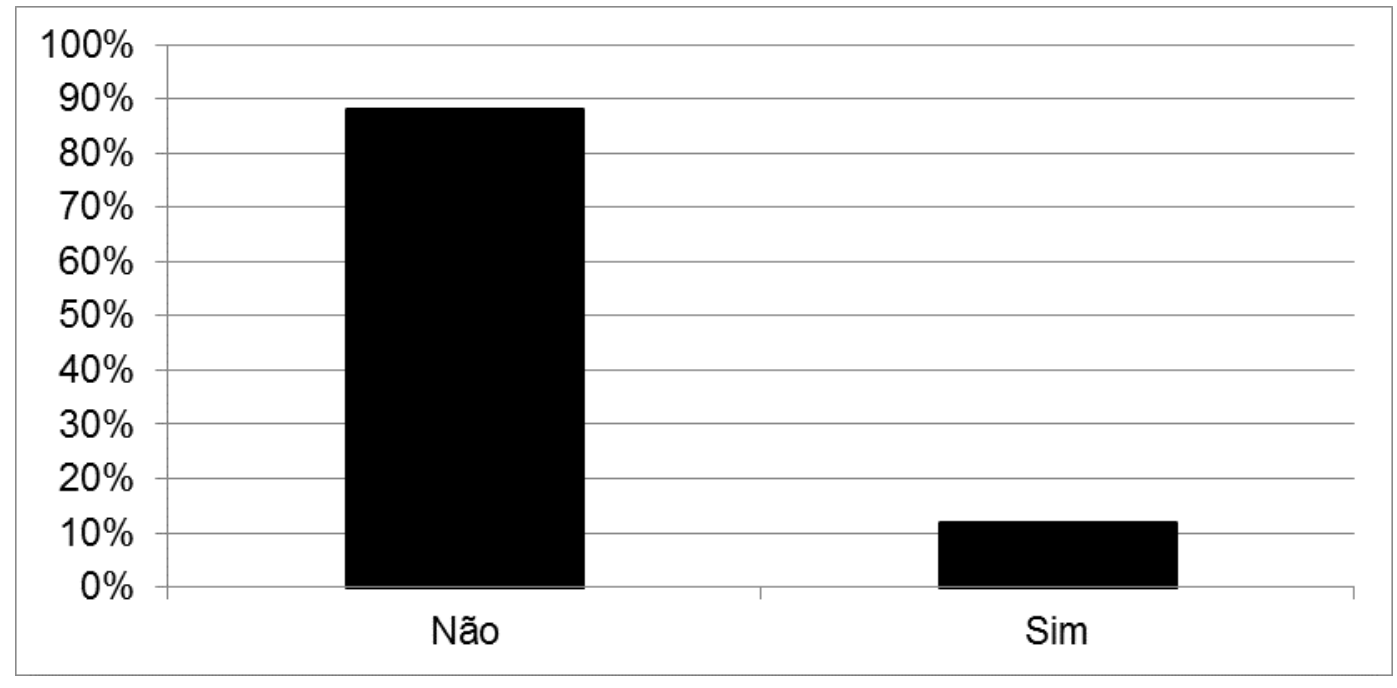

Fonte: Trabalho empírico - 2016

O resultado mostra que $12 \%$ dos docentes entrevistados já sofreram casos de violência praticados por pais ou responsáveis pelos alunos, enquanto a maioria, com 88\%, nunca sofreram violências dessas pessoas. Já acerca dos tipos de violência, os resultados mostram que todos os casos foram de agressões verbais.

A Figura 7 demostra a proporção de docentes que já sofreram alguma violência praticada por outro docente ou servidor da escola estadual de ensino médio de Leópolis pesquisada. Os dados expostos mostram que $16 \%$ dos docentes entrevistados afirmaram que já sofreram violência praticada por outro docente ou servidor da escola pesquisada, enquanto $84 \%$ dos docentes nunca enfrentaram uma violência praticada por outro docente ou servidor da escola. É um patamar elevado de docentes que sofreram violência praticada por outro docente ou servidor da escola. 
Figura 7: Leópolis (PR). Escola Estadual de Ensino Médio. Violências praticadas por docentes e servidores contra os docentes

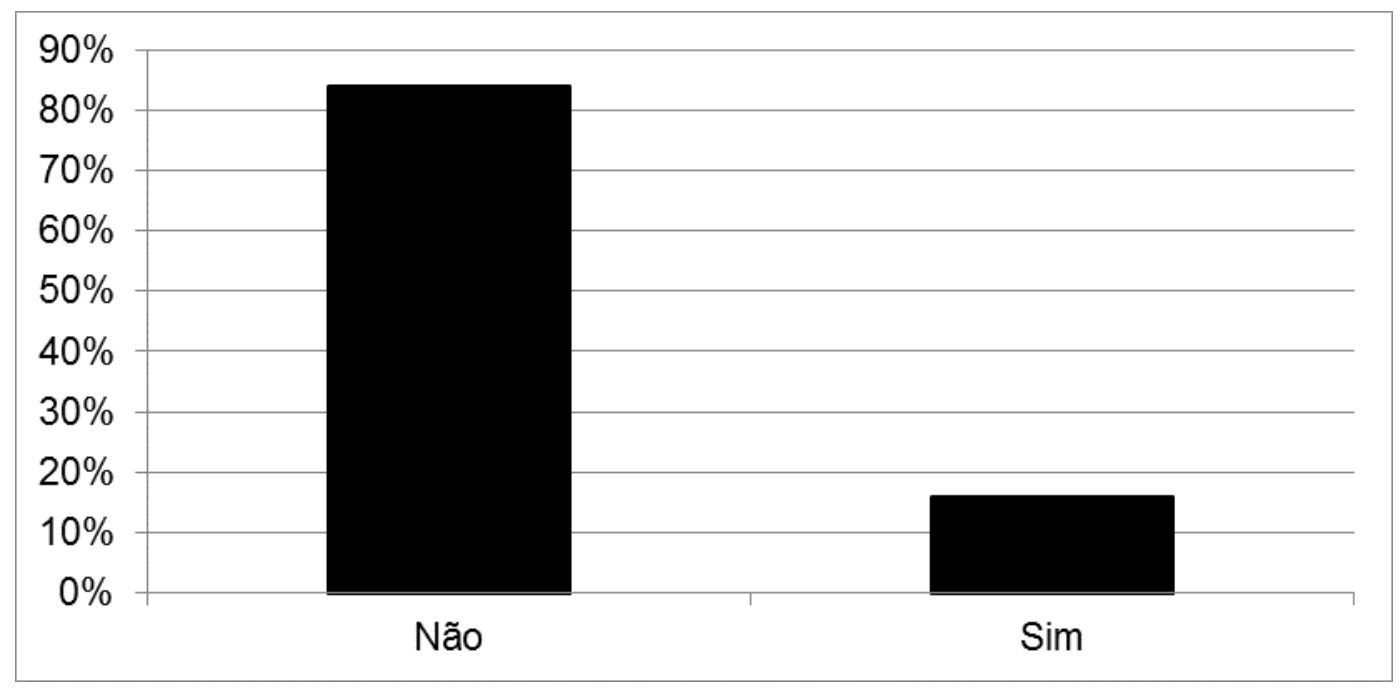

Fonte: Trabalho empírico - 2016

Entre os docentes que vivenciaram uma ocorrência de violência dentro da escola pesquisa praticada por outro docente ou servidor da mesma escola, todos (100\%) afirmaram que a violência ocorrida foi "agressão verbal" e "coações". Dentro desse debate, é importante pontuar que ao longo da aplicação dos questionários, nenhum docente respondente indicou a existência de ações da própria escola ou mesmo do Estado de modo a reverter essa situação. Logo, como debatido teoricamente, uma das consequências da violência contra o docente no espaço escolar está na saúde emocional. Para Costa (2013, p. 94), por exemplo, a "agressão contra o docente resulta em comprometimento da sua saúde emocional".

Nesse sentido, a Figura 8 apresenta informações sobre os docentes que já saíram de licença médica na escola estadual de ensino médio de Leópolis. Os dados demonstraram que $44 \%$ dos professores já saíram de licença médica na escola pesquisada, enquanto que $56 \%$ nunca solicitaram essa licença. Mais uma vez, é importante realçar que o valor é consideravelmente elevado. 
Figura 8: Leópolis (PR). Escola Estadual de Ensino Médio. Proporção de docentes que já saíram de licença médica.

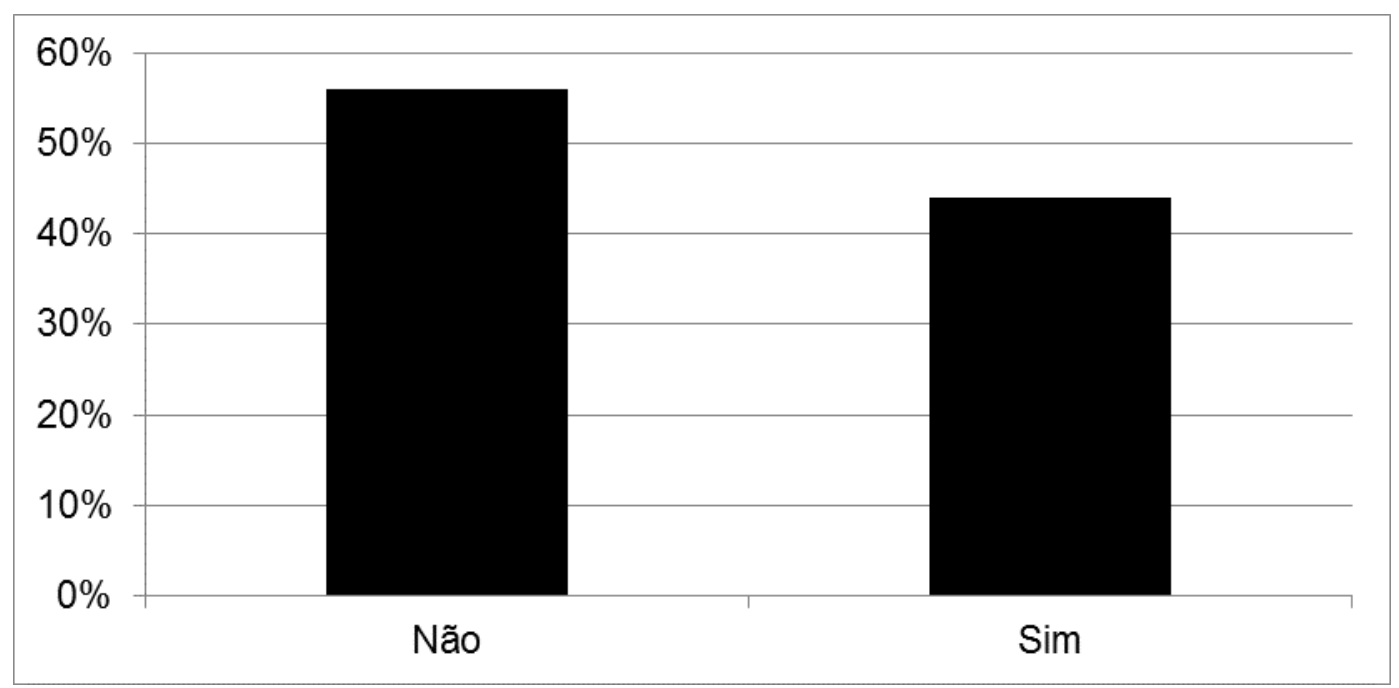

Fonte: Trabalho empírico - 2016

A Figura 9 demonstra os motivos que levaram esses docentes da escola a solicitarem o afastamento médico. Entre os professores que pediram afastamento, os motivos foram: síndrome do pânico e nódulos nas cordas vocais. Os dados apresentaram que $82 \%$ saíram por "síndrome do pânico" e 18\% por "nódulos nas cordas vocais".

Assim, os afastamentos médicos na escola pesquisada têm mais relação com o ambiente - violência e estresse - do que propriamente com o organismo do docente, ou seja, não tem um fundo natural, mas decorre de consequências ligadas à atividade docente diária. Aqueles que saíram de licença médica, por motivo da síndrome do pânico, estão diretamente vinculados ao fenômeno da violência. Em alguns casos, os nódulos nas cordas vocais também podem estar vinculado ao desconforto diário de ter que chamar a atenção, elevar a voz para ser ouvido, entre outras ações. Além disso, muitos dos docentes respondentes pontuaram o sentimento de depressão embora nenhum deles tenha se afastado oficialmente por esse motivo. 
Figura 9: Leópolis (PR). Escola Estadual de Ensino Médio. Motivos para os afastamentos de saúde

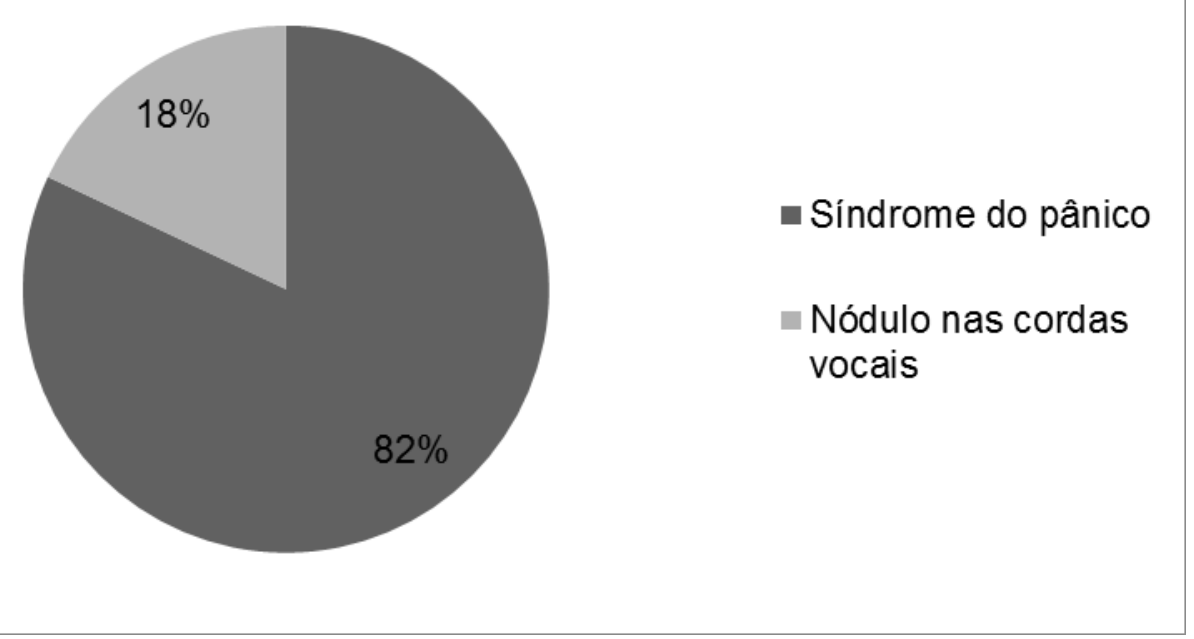

Fonte: Trabalho empírico - 2016

Por consequência disso, $24 \%$ dos docentes da escola estadual de ensino médio campo de estudo já pensaram em abandonar a profissão, ou seja, quase um a cada quatro docentes. É fundamental tentar entender a motivação para esses valores, pois como já abordado anteriormente, influenciam no ensino e aprendizagem e na própria saúde do professor. Apenas dois motivos foram citados pelos entrevistados na escola estadual de ensino médio: "desvalorização profissional" e "indisciplina por parte dos alunos", sendo que cada motivação concentrou metade das respostas: $50 \%$ cada.

A desvalorização profissional engloba plano de carreira e políticas públicas do Governo do Estado do Paraná para o professor, como capacitação e disponibilidade de infraestrutura. Já a segunda refere-se ao comportamento dos alunos, que muitas vezes são violentos e acabam ameaçando professores, agredindo (fisicamente e verbalmente), etc.

Além disso, $28 \%$ dos docentes responderam que existem conflitos entre os servidores da escola, enquanto a maioria, com $72 \%$ dos docentes, nunca sofreram com um conflito entre servidores da escola. Entre o grupo de professores que afirmaram a ocorrência de conflitos entre os servidores, a totalidade pontuou que o principal motivo para os conflitos é a "falta de companheirismo entre os colegas de trabalho", o que poderia ser enfrentado com ampliação do diálogo e de ações do Estado. 
Então, é preciso colocar luz sobre isso para ajudar inúmeros docentes que vivenciam uma situação de pânico, sobretudo na atual realidade onde, na maioria das vezes, os professores não encontram apoio nas instituições e órgãos públicos (SILVA, 2010). A sociedade, por sua vez, deve valorizar a profissão do educador, cobrando das autoridades que o professor tenha o devido apoio com acompanhamento jurídico e médico quando se sentir agredido (SILVA, 2010).

Com base nas análises realizadas constatou-se que os docentes têm consciência da violência no ambiente escolar. Por meio dos questionários pode-se perceber que a maioria dos docentes entrevistados sofreu com a violência escolar, sendo elas a agressão verbal e as ameaças. Durante as entrevistas, pode-se perceber que muitos docentes estão afastados da sala de aula, especialmente por síndrome do pânico. Assim, os resultados do trabalho empírico sinalizam que existe um problema sério de violência contra os docentes e que é preciso ampliar as ações do Estado na escola de forma a melhorar a condição do ensino-aprendizagem a partir de uma cultura da paz e da não violência.

\section{CONSIDERAÇÕES FINAIS}

A violência é um tema complexo, relevante e recorrente. Assim, este artigo teve como objetivo central compreender as representações sociais da violência contra o docente em um espaço escolar estadual de Leópolis, no Norte do Paraná. A violência escolar contra o docente é um problema que atinge as instituições escolares em diversas partes do Brasil, como é comumente noticiado na mídia e nos trabalhos acadêmicos. Por isso, o tema precisa ser estudado de forma aprofundado, visto que a escola é local privilegiado de aprendizagem e de socialização.

Vale ressaltar que ao longo da aplicação dos questionários, foi possível constatar que os docentes respondentes possuem uma percepção de que há um aumento da violência na escola e que isso não ocorre apenas por ação dos alunos, mas que a violência tem ocorrido também por ação de outros docentes e/ou demais servidores da escola e por pais e responsáveis dos alunos. 
Partindo da análise dos dados das entrevistas com os docentes, percebeu-se que dos tipos violências sofridas, em primeiro lugar, está a agressão verbal e, em seguida, as ameaças - em menor escala. É importante relembrar que baseado em diversos autores, contemplados no decorrer da investigação, o conceito de violência contra o professor se refere a toda forma de agressão física ou moral, provocada por alunos, pais de alunos e a própria instituição, dentro do ambiente escolar, causando danos à integridade física e moral dos professores.

Na escola de ensino médio de Leópolis pesquisada, a violência é uma realidade no ambiente escolar. Foi possível constatar que a maioria dos docentes que saíram de licença médica alegou ser por motivo de síndrome do pânico, reflexo da violência sofrida por diferentes atores e, também, pela indisciplina de alunos. Então, o problema é mais social do que de enfermidade do docente.

Portanto, a partir das análises e discussões realizadas pode-se concluir que a violência escolar é uma realidade que não deve ser mais negligenciada, sendo de suma importância que as autoridades públicas, educadores, família e sociedade estejam engajados para enfrentar as situações de violência que ocorrem na escola, que, por sua vez, tem deixado de ser um espaço seguro de socialização e trocas de conhecimentos e tem se tornado um "palco" de inúmeras cenas de violências.

Por outro lado, a escola precisa resistir e mostrar que ela mesma - por essência - é um espaço de transformação de realidades inadequadas. Ou seja, a transformação desses espaços violentos em espaços não violentos depende de ações da própria escola - em consonância com políticas públicas e engajamento de toda a comunidade - para, enfim, ocorrer a promoção de uma educação voltada para a paz.

\section{REFERÊNCIAS}

ABRAMOVAY, M.; RUA, M.G. Violências nas escolas. 2. ed. Brasília: UNESCO, 2002.

CHARLOT, B. A violência na escola: como os sociólogos franceses abordam essa questão. Revista Sociologias, Porto Alegre/RS, n.8, jul/dez, 2002.

COSTA, C.R.C. A hora da Violência contra o Docente nas Escolas particulares de Minas Gerais: uma abordagem espacial exploratória. In: X ENANPEGE - Encontro Nacional da Associação Nacional de Pós-Graduação em Geografia, Campinas, 2013. 
FERNANDES, Pedro Henrique Carnevalli. Um espectro ronda as pequenas cidades: 0 aumento da violência e da insegurança objetiva.2017. 525 p. Tese (Doutorado) - Programa de Pós-Graduação em Geografia da Universidade Estadual de Maringá, Maringá (PR), 2017.

IBGE. Instituto Brasileiro de Geografia e Estatística. Censo Demográfico. 2010. Disponível em: http://www.censo2010.ibge.gov.br/resultados_do_censo2010.php acesso em: 3 mar. 2018.

IBGE. Instituto Brasileiro de Geografia e Estatística. Divisão Regional. 2008. Disponível em: http://www.ibge.gov.br/home/geociencias/geografia/default_div_int.shtm acesso em: 10 mar. de 2018.

IPARDES, Instituto Paranaense de Desenvolvimento Econômico e Social. Cadernos municipais: Leópolis. Disponível em: http://www.ipardes.gov.br/cadernos/Montapdf.php?Municipio=86330\&btOk=ok. acesso em: 30 abr. de 2018.

LEÓPOLIS, Prefeitura Municipal. Leópolis. 2018. Disponível em: www.leopolis.pr.gov.br acesso em: 30 abr. de 2018.

LOPES, C. S. A violência nas escolas de Maringá, Estado do Paraná. Acta Sci. Human Soc. Sci., Maringá, v. 30, n. 1, p. 35-44, 2008. Disponível em: http://eduem.uem.br/ojs/index.php/ActaSciHumanSocSci/article/viewFile/2482/3306. Acesso em: 04 mar de 2017.

LOPES, C. S. A violência no espaço escolar e a relação professor-aluno. UEM, Maringá. Dissertação de Mestrado (Mestrado em Educação). Universidade Estadual de Maringá, 2001.

LOPES C. S.; GASPARIN, J. L. Violência e conflitos na escola: desafios à prática docente. Acta Sci. Human Soc. Sci., Maringá, v. 25, n. 2, p. 295-304, 2003.

MARRA, C. A. S. Violência escolar: um estudo de caso sobre a percepção dos atores escolares a respeito dos fenômenos de violência explícita e sua repercussão no cotidiano da escola. 2004. $227 \mathrm{f}$. Dissertação (mestrado) - Pontifícia Universidade Católica de Minas Gerais, Belo Horizonte, 2004.

PEREIRA, A. C. S; WILLIAMS, L. C. A. Reflexões sobre o conceito de violência escolar e a busca por uma definição abrangente. Laboratório de Análise e Prevenção da Violência: Temas em Psicologia - 2010 Vol. 18, no 1, 45 - 55 - Universidade Federal de São Carlos (UFSCar), 2010.

PRIOTTO, E. P; BONETI, L. W. Violência Escolar: na escola, da escola e contra a escola. Rev. Diálogo Educ., Curitiba, v. 9, n. 26, p. 161-179, jan./abr. 2009.

ROSA, M. J. A. Violência no ambiente escolar: refletindo sobre as consequências para o processo ensino aprendizagem. Itabaiana: GEPIADDE, 2010.

SCHILLING, F. A sociedade da insegurança e a violência na escola. São Paulo: Moderna, 2004.

SILVA, R. C. S. Violência contra o professor: efeitos devastadores. 2010. Encontro de Formação de Professores da Universidade Trindade. Disponível em: http://www.unit.br/hotsites/2010/enc_formacao_professores/arquivos/GT01/SILVA. Acesso: 03 mar. de 2017.

SOARES, M. B. Representações sociais de violência contra professores na escola. 2013. $179 \mathrm{f}$. Dissertação (Mestrado) - Universidade Federal de Pernambuco: UFPE, 2013.

SOARES, M. B; MACHADO, L. B. Violência contra o professor nas representações sociais de docentes. Revista Perspectiva, Florianópolis, v. 32, n. 1, 333-354, jan./abr. 2014. Disponível em: https://periodicos.ufsc.br/index.php/perspectiva/article/view/2175-795X.2014v32n1p333. Acesso em: 08 mar. 2017. 
SOARES, M. B; MACHADO, L. B. Violência contra o Professor: sentidos compartilhados e práticas Docentes frente ao fenômeno. 36 ${ }^{a}$ Reunião Nacional da ANPEd. Goiânia-GO. Disponível em: http://36reuniao.anped.org.br/pdfs_trabalhos_aprovados/gt20_trabalhos_pdfs/gt20_3139_texto.pdf . Acesso em: 08 mar. 2017

SODRÉ, C. M. O. Violência no espaço escolar. Revista Eventos Pedagógicos, v.3, n.2, p. 315 - 327, Maio - Jul.2012. Disponível em: http://sinop.unemat.br/projetos/revista/index.php/eventos/article/viewFile/665/484 . Acesso em: 08 mar. 2017

TEIXEIRA, M. C. S; PORTO, M. R. S. Imaginário do medo e cultura da violência na escola. Niterói: Intertexto, 2004. 